
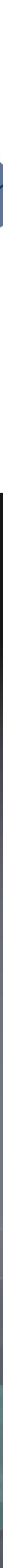


\section{A) Check for updates}

Cite this: Polym. Chem., 2020, 11 5981

Received 6th March 2020

Accepted 19th June 2020

DOI: $10.1039 / \mathrm{d} 0$ py00353k

rsc.li/polymers

\title{
Kinetic modeling study of the group-transfer polymerization of alkyl crotonates using a silicon Lewis acid catalyst $\dagger$
}

\author{
Motosuke Imada, (DD a,b,c Yasumasa Takenaka, (D) *a Takeharu Tsuge (iD ${ }^{b}$ and \\ Hideki Abe ${ }^{a, b}$
}

\begin{abstract}
Kinetic modeling is effective in the development of efficient and manageable polymerization systems. Herein, a kinetic model of the group-transfer polymerization (GTP) of an alkyl crotonate using a silicon Lewis acid catalyst having a trialkylsilyl (trimethylsilyl, triethylsilyl, tert-butyldimethylsilyl, or triisopropylsilyl) moiety and various silyl ketene acetals with a corresponding trialkylsilyl moiety as an initiator is developed to understand the polymerization mechanism. The kinetic model quantitatively verifies proposed elementary reactions. When using a trimethylsilyl moiety, the activation energy of the cyclization reaction (a wellknown termination reaction in GTP; $\left.E_{\mathrm{C}}=37.8 \mathrm{~kJ} \mathrm{~mol}^{-1}\right)$ exceeds that of the propagation reaction $\left(E_{\mathrm{p}}=\right.$ $28.6 \mathrm{~kJ} \mathrm{~mol}^{-1}$ ). This reveals that termination reactions are accelerated more than propagation reactions at high temperatures. In addition, comparison of various trialkylsilyl moieties confirmed that the greater bulkiness of the alkyl substituent on the silyl group increases the ratio of the activation energies of the cyclization and propagation reactions.
\end{abstract}

\section{Introduction}

Crotonic acid (CA) and its derivatives, such as crotonates, are structural isomers of methacrylic acid and its derivatives. A methyl group exists at the $\beta$-position of these $\alpha, \beta$-unsaturated carboxylic compounds. ${ }^{1,2}$ Because of $\beta$-substituent steric hindrance and/or an electronic factor, there are well-known difficulties in using these compounds as monomers to produce homopolymers with high molecular weights via conventional radical polymerization methods based on 2,2'-azobisisobutyronitrile or benzoyl peroxide and via typical anionic polymerization methods based on alkyl lithium or Grignard reagents. $^{3-7}$

Recently, we reported the group-transfer polymerization (GTP) method for the homopolymerization of various alkyl crotonates using only an organic acid catalyst, such as $\mathrm{N}$-(trimethylsilyl)bis(trifluoromethanesulfonyl)imide $\left(\mathrm{Tf}_{2} \mathrm{NSiMe}_{3}\right)$, which is a silicon Lewis acid (LA), and 1-trimethylsiloxyl-1-

\footnotetext{
${ }^{a}$ Bioplastic Research Team, RIKEN Center for Sustainable Resource Science, 2-1 Hirosawa, Wako, Saitama 351-0198, Japan.

E-mail: yasumasa.takenaka@riken.jp

${ }^{b}$ Department of Materials Science and Engineering, Tokyo Institute of Technology, 4259 Nagatsuta, Midori-ku, Yokohama 226-8502, Japan

${ }^{c}$ Research Center, Innovation and Business Development Division, Nippon Shokubai Co., Ltd, 5-8 Nishi Otabi-cho, Suita, Osaka 564-0034, Japan

$\dagger$ Electronic supplementary information (ESI) available. See DOI: 10.1039/ d0py00353k
}

methoxy-2-methyl-1-propene (MTS) as the initiator. ${ }^{8,9}$ In general, organocatalysis without metal compounds is beneficial for industrial applications because of the well-known advantages of metal-free polymeric products and processes. $^{10,11}$

However, the alkyl crotonate GTP mentioned above is usually performed at low temperatures (preferably $-40{ }^{\circ} \mathrm{C}$ or below) because high reaction temperatures, even ambient temperatures, accelerate termination reactions such as cyclization and/or isomerization of propagating chain-end groups. ${ }^{12-15}$ Briefly, despite the living-polymerization characteristics of GTP, the propagation reaction declines, with the unreacted monomer remaining after the reaction ceases. Consequently, a polymeric material with a molecular weight that is sufficiently large to realize high-performance applications cannot be produced. Furthermore, the requirement of such low temperatures severely limits the application of GTP to industrial processes. ${ }^{16,17}$

The construction of a kinetic model is an effective approach toward the development of efficient and manageable polymerization systems that operate at high temperatures. The kinetic model quantitatively demonstrates the elementary reactions and provides useful knowledge related to the polymerization mechanism and design of optimum polymerization systems.

Herein, we develop a kinetic model of the GTP of alkyl crotonates using silicon LA catalysts having a trialkylsilyl moiety 
$\left(\mathrm{Tf}_{2} \mathrm{NSiR} 1 \mathrm{R} 2 \mathrm{R} 3\right)$ and various silyl ketene acetals $\left({ }^{\mathrm{R} 1 \mathrm{R} 2 \mathrm{R} 3} \mathrm{SKAs}\right)$ as the initiator. The kinetic model includes monomer activation steps, propagation reactions of living species, and termination reactions of living species. Furthermore, various trialkylsilyl moieties are compared and analyzed to investigate steric hindrance effects.

\section{Experimental}

\section{Materials}

Methyl crotonate (MC), ethyl crotonate (EC), 1-trimethylsiloxyl1-methoxy-2-methyl-1-propene (MTS), methyl isobutyrate, chlorotriethylsilane, tert-butyldimethylchlorosilane, chlorotriisopropylsilane, $N, N$ '-dimethylpropyleneurea, lithium(diisopropylamide) (1.5 M in THF), $N$-(trimethylsilyl)bis(trifluoromethanesulfonyl)imide $\left(\mathrm{Tf}_{2} \mathrm{NSiMe}_{3}\right)$, and bis(trifluoromethanesulfonyl)imide $\left(\mathrm{Tf}_{2} \mathrm{NH}\right)$ were obtained from Tokyo Chemical Industry Co., Ltd (TCI). Distillation using $\mathrm{CaH}_{2}$ was performed for MC, EC, and MTS before they were stored in a glovebox. $\mathrm{CH}_{2} \mathrm{Cl}_{2}$, THF, and 1,2-dichloroethane (Kanto Chemical Co., super dehydrated grade) were purified using an SPS 800 system (MBraun). Argon and nitrogen were used after purification by passing them through a dry clean column (4A molecular sieves) and a gas clean CC-XR column (Nikka Seiko).

\section{Synthesis of silyl ketene acetal (SKA)}

1-Methoxy-1-(triethylsiloxy)-2-methyl-1-propene ( $\left.{ }^{\mathrm{Et}_{3}} \mathrm{SKA}\right)$ was synthesized via the reaction of methyl isobutyrate and chlorotriethylsilane, in accordance with a method reported in the literature. ${ }^{18}$ Methyl isobutyrate $(14.0 \mathrm{~g}, 137 \mathrm{mmol})$ in THF solution (200 mL) was charged into a flask filled with dry nitrogen gas, following which $1.5 \mathrm{M}$ lithium(diisopropylamide) (100 mL, $150 \mathrm{mmol}$ ) in THF was added dropwise with vigorous stirring at $-78{ }^{\circ} \mathrm{C}$ for $30 \mathrm{~min}$. Subsequently, $N, N$ '-dimethylpropyleneurea $(200 \mathrm{mmol})$ and chlorotriethylsilane $(22.6 \mathrm{~g}$, $150 \mathrm{mmol})$ in THF solution $(50 \mathrm{~mL})$ were added, and the reagents were stirred at $-78{ }^{\circ} \mathrm{C}$ for $60 \mathrm{~min}$, following which they were warmed to room temperature. The reagents were then stirred for $24 \mathrm{~h}$ at room temperature, following which they were concentrated. The resulting mixture was taken in $500 \mathrm{~mL}$ of hexane and washed with $100 \mathrm{~mL}$ of water thrice. Next, the mixture was washed with $100 \mathrm{~mL}$ of saturated aq. $\mathrm{NaHCO}_{3}$ and $100 \mathrm{~mL}$ of brine and subsequently dried over $\mathrm{MgSO}_{4}$. After filtration, the organic layer was concentrated. Distillation under vacuum resulted in a 90\% yield of ${ }^{\mathrm{Et}_{3}} \mathrm{SKA}$ as a clear colorless liquid with purity $>97 \%$, as measured using ${ }^{1} \mathrm{H}$ nuclear magnetic resonance (NMR). 1-Methoxy-1-(tertbutyldimethylsiloxy)-2-methyl-1-propene $\quad\left({ }^{t \mathrm{BuMe}_{2}} \mathrm{SKA}\right) \quad(54 \%$ yield as a clear colorless liquid with purity $>99 \%$ ) and 1-methoxy-1-(triisopropylsiloxy)-2-methyl-1-propene $\quad\left({ }^{\mathrm{iPr}_{3}} \mathrm{SKA}\right)$ (70\% yield as a clear colorless liquid with purity $>97 \%$ ) were synthesized in a similar manner.

\section{Measurements}

All molecular weight data of polymer samples were obtained through size exclusion chromatography (SEC) at $40{ }^{\circ} \mathrm{C}$ using a Shimadzu GPC system equipped with a RID-10A refractive index detector, a Shodex GPC K-802 column, and a Shodex GPC $\mathrm{K}-806 \mathrm{M}$ column. $\mathrm{CHCl}_{3}$ was used as an eluent at a flow

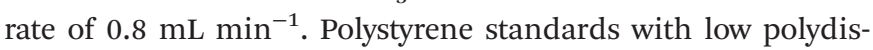
persity values were used to draw the calibration curve.

Matrix-assisted laser desorption/ionization time-of-flight mass spectroscopy (MALDI-TOF-MS) was conducted using an ultrafleXtreme MALDI-TOF spectrophotometer (Bruker Daltonics, Billerica, MA) operated in reflection mode at an accelerating voltage of $20 \mathrm{kV}$. The samples that underwent MALDI-TOF-MS were combinations of the reaction mixture $(2 \mu \mathrm{L})$, the matrix (1,8-dihydroxy-9 $(10 H)$-anthracenone (dithranol), $10 \mathrm{mg} \mathrm{mL} \mathrm{m}^{-1}, 8 \mu \mathrm{L}$ ), and the ionizing agent (sodium trifluoroacetate, $10 \mathrm{mg} \mathrm{mL} \mathrm{m}^{-1}, 2 \mu \mathrm{L}$ ) in THF. These samples were deposited on an MTP 384 ground steel target plate TF in a glovebox. External calibration was conducted prior to data acquisition. The detected mass list was extracted using FlexAnalysis software (Bruker Daltonics).

${ }^{1} \mathrm{H}$ and ${ }^{13} \mathrm{C}$ NMR measurements were performed with a Varian NMR system. The samples were dissolved in $\mathrm{CDCl}_{3}$, and $500 \mathrm{MHz}{ }^{1} \mathrm{H}$ NMR and $125 \mathrm{MHz}{ }^{13} \mathrm{C}$ NMR spectra were recorded at room temperature. The data were calibrated against tetramethylsilane (TMS, $\delta 0.00)$ and analyzed using the Mnova NMR software.

\section{Group-transfer polymerization}

All manipulations were performed under a dry and oxygen-free argon atmosphere using standard high-vacuum Schlenk techniques or a glovebox. A typical polymerization procedure (entry 1, Table 1) is as follows: EC (2.85 g, $25 \mathrm{mmol})$, MTS (10.9 mg, $0.0625 \mathrm{mmol})$, and $\mathrm{CH}_{2} \mathrm{Cl}_{2}(6 \mathrm{~mL})$ were charged into a Schlenk tube in a glovebox. $\mathrm{A} \mathrm{CH}_{2} \mathrm{Cl}_{2}$ solution $\left(3.4 \mathrm{~mL}\right.$ ) of $\mathrm{Tf}_{2} \mathrm{NSiMe}_{3}$ (22.1 $\mathrm{mg}, 0.0625 \mathrm{mmol}$ ) was added to initiate the polymerization reaction at $-40{ }^{\circ} \mathrm{C}$. After $8 \mathrm{~h}$, methanol $(10 \mathrm{~mL})$ was added to the reaction mixture, following which the solvents were removed by evaporation under reduced pressure. The residue was dissolved in $\mathrm{CHCl}_{3}$, and the solution was poured into a large volume of hexane. The precipitated polymer was collected as the hexane-insoluble part by filtration, washed several times with hexane, and dried under vacuum for $24 \mathrm{~h}$. The hexane-soluble part was obtained by the evaporation of the filtrate, followed by drying under vacuum for $24 \mathrm{~h}$. The monomer conversion was calculated from the sum of the weights of the hexane-insoluble and hexane-soluble parts.

\section{Computational method}

Theoretical calculations were performed using the Gaussian 09 software package. ${ }^{19}$ All the computations employed in this study were performed using density functional theory (DFT) with the B3LYP functional. Geometrical optimizations were performed using the $6-31 \mathrm{G}^{*}$ basis set. $^{20,21}$ 
Table 1 Results of EC polymerization using $\mathrm{Tf}_{2} \mathrm{NSiMe}_{3} / \mathrm{MTS}$ at $-40{ }^{\circ} \mathrm{C}$

\begin{tabular}{|c|c|c|c|c|c|c|c|c|}
\hline Entry & {$[\mathrm{EC}]_{0}(\mathrm{M})$} & {$[\mathrm{MTS}]_{0}(\mathrm{M})$} & {$\left[\mathrm{Tf}_{2} \mathrm{NSiMe}_{3}\right]_{0}(\mathrm{M})$} & Time (h) & Conv. $^{b}(\%)$ & $M_{\mathrm{n}}^{c}\left(\mathrm{~g} \mathrm{~mol}^{-1}\right)$ & $\bigoplus^{c}\left(M_{\mathrm{w}} / M_{\mathrm{n}}\right)$ & $v_{\mathrm{app}}{ }^{d}\left(\mathrm{~mol} \mathrm{~L}^{-1} \mathrm{~h}^{-1}\right)$ \\
\hline 1 & 2.0 & 0.0050 & 0.0050 & 8 & 11.0 & 10000 & 1.17 & 0.0275 \\
\hline 2 & & & & 24 & 27.2 & 28300 & 1.14 & \\
\hline 3 & & & & 72 & 53.5 & 52800 & 1.29 & \\
\hline 4 & & & & 168 & 54.8 & 58300 & 1.32 & \\
\hline 5 & 2.0 & 0.0100 & 0.0050 & 8 & 18.1 & 12000 & 1.16 & 0.0453 \\
\hline 6 & & & & 24 & 47.5 & 33300 & 1.14 & \\
\hline 7 & & & & 72 & 83.2 & 58200 & 1.27 & \\
\hline 8 & & & & 168 & 83.5 & 59000 & 1.26 & \\
\hline 9 & 2.0 & 0.0200 & 0.0050 & 3 & 17.9 & 4100 & 1.20 & 0.1195 \\
\hline 10 & & & & 7 & 40.6 & 11100 & 1.17 & \\
\hline 11 & & & & 16 & 89.1 & 27300 & 1.17 & \\
\hline 12 & & & & 24 & 100.0 & 31500 & 1.14 & \\
\hline 13 & & & & 48 & 99.9 & 31400 & 1.14 & \\
\hline 14 & & & & 72 & 100.0 & 30700 & 1.16 & \\
\hline 15 & 1.5 & 0.0050 & 0.0050 & 8 & 17.0 & 11600 & 1.16 & 0.0319 \\
\hline 16 & & & & 24 & 39.9 & 37400 & 1.11 & \\
\hline 17 & & & & 72 & 65.1 & 65000 & 1.25 & \\
\hline 18 & & & & 168 & 64.6 & 60400 & 1.28 & \\
\hline 19 & 1.0 & 0.0050 & 0.0050 & 4 & 15.9 & 6800 & 1.21 & 0.0398 \\
\hline 20 & & & & 8 & 26.7 & 15300 & 1.18 & \\
\hline 21 & & & & 24 & 63.2 & 40100 & 1.18 & \\
\hline 22 & & & & 72 & 75.6 & 52300 & 1.26 & \\
\hline 23 & 1.0 & 0.0025 & 0.0025 & 24 & 23.2 & 24800 & 1.16 & 0.0097 \\
\hline 24 & & & & 72 & 44.3 & 46900 & 1.28 & \\
\hline 25 & & & & 168 & 46.5 & 48800 & 1.34 & \\
\hline 26 & 1.0 & 0.0025 & 0.0100 & 6 & 18.5 & 20400 & 1.17 & 0.0308 \\
\hline 27 & & & & 12 & 30.9 & 34500 & 1.18 & \\
\hline 28 & & & & 24 & 43.3 & 47400 & 1.31 & \\
\hline 29 & & & & 72 & 46.3 & 52300 & 1.36 & \\
\hline 30 & & & & 168 & 46.3 & 53700 & 1.34 & \\
\hline 31 & 1.0 & 0.0025 & 0.0400 & 3 & 24.6 & 28600 & 1.19 & 0.0820 \\
\hline 32 & & & & 6 & 38.2 & 47200 & 1.19 & \\
\hline 33 & & & & 24 & 46.6 & 57000 & 1.33 & \\
\hline 34 & & & & 72 & 52.3 & 58300 & 1.41 & \\
\hline 35 & & & & 168 & 47.6 & 57100 & 1.31 & \\
\hline
\end{tabular}

${ }^{a}$ Performed on an aluminum block under an argon atmosphere. $\mathrm{CH}_{2} \mathrm{Cl}_{2}$ was used as the reaction solvent. ${ }^{b}$ Monomer conversion was calculated from the sum of the weights of the hexane-insoluble and hexane-soluble parts. ${ }^{c}$ Number-averaged molecular weight $\left(M_{\mathrm{n}}\right)$ and dispersity $(\nexists)$ were determined using conventional GPC against PSt standards in $\mathrm{CHCl}_{3} \cdot{ }^{d}$ Apparent rate of monomer consumption during an initial period ( $v_{\text {app}}$ ) was calculated using the first data point for each condition.

\section{Results and discussion}

\section{GTP of crotonates using a silicon LA catalyst}

Fig. 1 shows a plausible polymerization mechanism for the GTP of crotonates using a silicon LA catalyst. ${ }^{8}$ First, a crotonate coordinates to a silicon LA catalyst, following which the activated monomer (active species) is generated. The activated monomer reacts with the initiator or the living polymer, which possesses a structure similar to that of the initiator at the polymer chain-end. Consequently, the polymer chain grows, and a silicon LA catalyst unit is released. The living polymer is elongated by repeating this process. The kinetic model in this study was constructed based on the pathway mentioned above but with the addition of new concepts, regarding the association between the monomer and the silicon LA catalyst as well as concerning the termination reactions.

\section{Determination of rate orders}

First, experiments were conducted for the polymerization of EC using MTS as an initiator and $\mathrm{Tf}_{2} \mathrm{NSiMe}_{3}$ as the silicon LA catalyst under various conditions at $-40{ }^{\circ} \mathrm{C}$ to evaluate the individual effects of concentrations of the monomer, initiator, and silicon LA catalyst. Table 1 lists the monomer conversions and the apparent rates of monomer consumption in an initial period $\left(v_{\text {app }}\right)$ under various conditions.

In order to investigate the reaction order for each concentration of the initiator, monomer, and silicon LA catalyst, double-logarithmic plots of $v_{\text {app }}$ versus $[\mathrm{MTS}]_{0},[\mathrm{EC}]_{0}$, and $\left[\mathrm{Tf}_{2} \mathrm{NSiMe}_{3}\right]_{0}$ were fit to straight lines (Fig. 2(a)-(c)). For the initiator, the slope of the straight line drawn using three data points $\left([\mathrm{MTS}]_{0}=0.0050,0.010\right.$, and $0.020 \mathrm{M} ;[\mathrm{EC}]_{0}=2.0 \mathrm{M}$; $\left[\mathrm{Tf}_{2} \mathrm{NSiMe}_{3}\right]_{0}=0.0050 \mathrm{M}$ ) (entries 1, 5, and 9 in Table 1) was $1.04\left(R^{2}=0.97\right)$. For the monomer, the slope of the straight line drawn using three data points $\left([\mathrm{MTS}]_{0}=0.0050 \mathrm{M} ;[\mathrm{EC}]_{0}=\right.$ 2.0, 1.5, and 1.0 M; $\left[\mathrm{Tf}_{2} \mathrm{NSiMe}_{3}\right]_{0}=0.0050 \mathrm{M}$ ) (entries 1, 15, and 19 in Table 1$)$ was $-0.53\left(R^{2}=1.00\right)$. For the silicon LA catalyst, the slope of the straight line drawn using three data points $\left([\mathrm{MTS}]_{0}=0.0025 \mathrm{M} ;[\mathrm{EC}]_{0}=1.0 \mathrm{M} ;\left[\mathrm{Tf}_{2} \mathrm{NSiMe}_{3}\right]_{0}=\right.$ $0.0025,0.010$, and $0.040 \mathrm{M}$ ) (entries 23, 26, and 31 in Table 1) was $0.77\left(R^{2}=1.00\right)$. The value of the slope corresponds to the reaction order of each component in the initial period. 


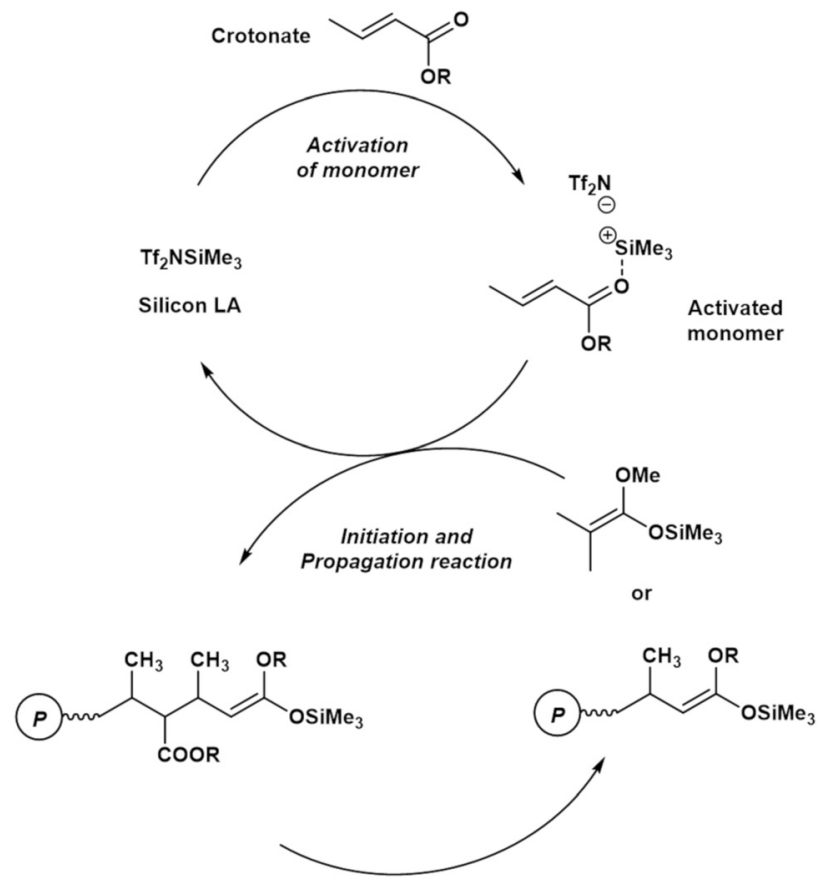

Fig. 1 Plausible propagation pathway for the GTP of a crotonate using a silicon LA catalyst (reproduced from Takenaka and $\mathrm{Abe}^{8}$ ).

The slope of the plot of $\ln \left[v_{\text {app }}\right]$ vs. $\ln [\text { MTS }]_{0}$ in Fig. 2(a) (1.04) suggests that the initial polymerization rate is almost of first order with respect to the initiator concentration. As shown in Fig. 1, this result implies that an initiator or a living polymer chain-end group undergoes a first-order reaction with an activated monomer generated by the coordination of a monomer to a silicon LA catalyst.

A notable feature of this polymerization system, observed from the analysis of the double-logarithmic plots of the apparent rates of the monomer consumption during the initial period, is that the polymerization rate order calculated with respect to the monomer concentration (slope, -0.53) is negative. Furthermore, the rate order with respect to the silicon LA catalyst concentration (slope, 0.77 ) is less than one, although this polymerization rate should be of first order when considering only the active-species formation from the reaction

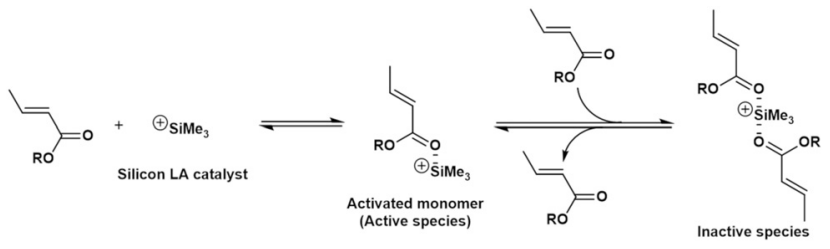

Scheme 1 Proposed equilibrium between the monomer and silicon LA catalyst.

between one monomer and one catalyst molecule. These peculiar results for the rate orders with respect to both the monomer and silicon LA catalyst concentrations suggest that the monomer reduces the polymerization rate while the silicon LA catalyst is somehow involved in this reduction. As shown in Scheme 1, we can express these peculiar rate orders with respect to the monomer and silicon LA catalyst concentrations by considering that one more monomer can coordinate with the activated monomer (active species) formed by the association of one silicon LA catalyst with one monomer, which leads to the formation of the inactive species.

\section{Evidence for the formation of a monomer/silicon LA catalyst (2/1) adduct}

A theoretical study was conducted to confirm that the generation of an inactive species, a monomer/silicon LA catalyst (2/1) adduct, is applicable to the present system. Fig. 3(a) and (b) show the structures of adduct $\mathrm{A}$ (active species, $\mathrm{EC} /{ }^{+} \mathrm{SiMe}_{3}=$ 1/1) and adduct $\mathrm{B}\left(\mathrm{EC} /{ }^{+} \mathrm{SiMe}_{3}=2 / 1\right)$ computed at the B3LYP/6$31 \mathrm{G}^{*}$ level of theory, respectively. As shown in Fig. 3(a), the length of the bond between the silicon $\mathrm{Si}(1 \mathrm{a})$ and oxygen $\mathrm{O}(1 \mathrm{a})$ atoms was $1.805 \AA$ for adduct $\mathrm{A}$; whereas, for adduct $\mathrm{B}$, as shown in Fig. 3(b), the lengths of the bonds between the silicon atom $\mathrm{Si}(1 \mathrm{~b})$ and the oxygen atoms $\mathrm{O}(1 \mathrm{~b})$ and $\mathrm{O}(2 \mathrm{~b})$ were $2.037 \AA$ and $2.078 \AA$, respectively.

This result suggests that, in both adduct $\mathrm{A}$ and adduct $\mathrm{B}$, the silicon atom of the silicon LA catalyst and the lone pair on the oxygen atoms of the carbonyl groups interact via the transfer of an electron because the bond lengths between them are sufficiently short. ${ }^{22,23}$ Therefore, this result can be considered as evidence for the presence of adduct B and adduct A. In (a)

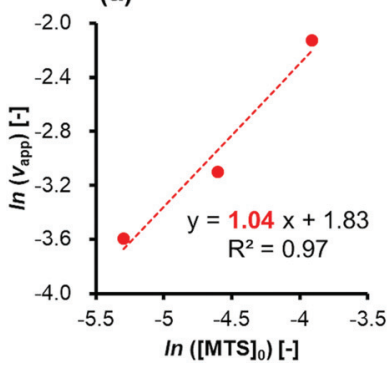

(b)

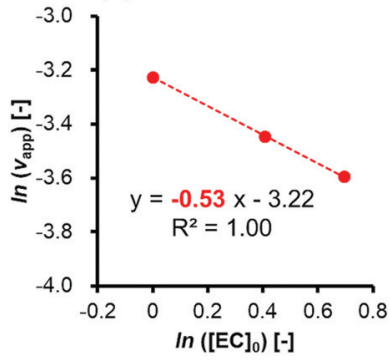

(c)

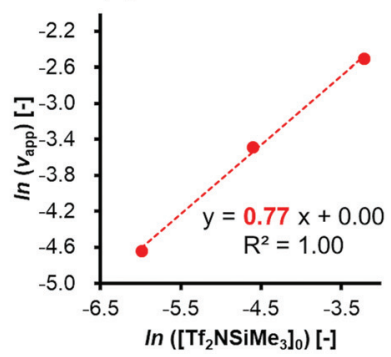

Fig. 2 Double-logarithmic plots of apparent rates of monomer consumption during an initial period ( $v_{\text {app }}$ ) as a function of (a) the initiator, (b) monomer, and (c) silicon LA catalyst. 
(a)

(b)
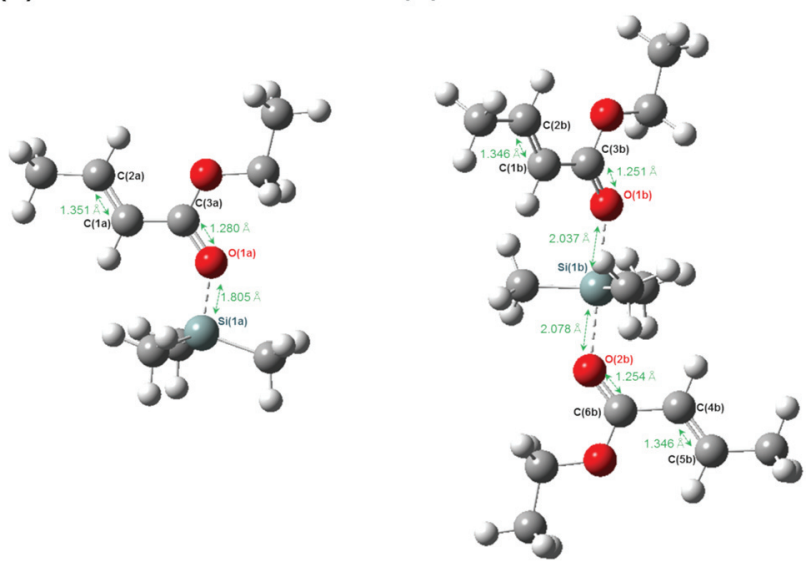

Fig. 3 Computed structures of (a) adduct $A\left(E C /{ }^{+} \mathrm{SiMe}_{3}=1 / 1\right)$ and (b) adduct $\mathrm{B}\left(\mathrm{EC} /{ }^{+} \mathrm{SiMe}_{3}=2 / 1\right)$ at the B3LYP/6-31G* level.

addition, because the bond lengths between the silicon and oxygen atoms of adduct $\mathrm{B}$ are longer than those between the silicon and oxygen atoms of adduct $\mathrm{A}$, the monomer activation degree of adduct $\mathrm{B}$ is lower than that of adduct $\mathrm{A}$. The length of the vinyl bonds of EC in adduct $B(C(1 b)=C(2 b)$ and $\mathrm{C}(4 \mathrm{~b})=\mathrm{C}(5 \mathrm{~b}), 1.346 \AA)$ is less than that in adduct $\mathrm{A}(\mathrm{C}(1 \mathrm{a})=\mathrm{C}$ (2a), $1.351 \AA$ ), although it is slightly longer than that in free EC, unbound to the silicon LA catalyst (1.339 ̊). In addition, the length of the carbonyl bonds of EC in adduct $\mathrm{B}(\mathrm{C}(3 \mathrm{~b})=\mathrm{O}$ (1b) and $\mathrm{C}(6 \mathrm{~b})=\mathrm{O}(2 \mathrm{~b}), 1.251 \AA$ and $1.254 \AA$, respectively) is less than that in adduct $\mathrm{A}(\mathrm{C}(3 \mathrm{a})=\mathrm{O}(1 \mathrm{a}), 1.280 \AA)$, although it is slightly longer than that in free EC $(1.217 \AA)$.

\section{Termination reactions on GTP of EC using a silicon LA catalyst}

Despite the living-polymerization characteristics of a GTP system, the use of EC as a monomer substrate resulted in a decline of the propagation reaction, with unreacted monomer remaining in all cases, as summarized in Table 1, except for the case of a low feed ratio between the monomer and initiator (entries 9-14 in Table 1). Furthermore, a previous report $^{8}$ stated that the GTP of alkyl crotonates generated not only polymers of a terminal cyclic form, via a well-known cyclization termination reaction, but also polymers of a linear form, via an acid treatment of a living polymer, as observed through the MALDI-TOF-MS analysis of the resulting polymers upon a halt of the polymerization reaction with unconsumed monomer remaining. This result suggests that some protic acids are produced in situ, which causes the protonation of a living polymer to occur in situ. In the present study, the termination mechanism was investigated in detail through a MALDI-TOF-MS analysis of the reaction mixture for the GTP of MC. The polymerization experiment was performed at $20^{\circ} \mathrm{C}$; at this temperature, termination reactions are promoted, with reduction of the monomer-to-initiator feed ratio for the ease of observation of products and/or intermediates.

Fig. 4(a) shows the MALDI-TOF-MS spectrum of the obtained reaction mixture. We can observe five series of mass (a)

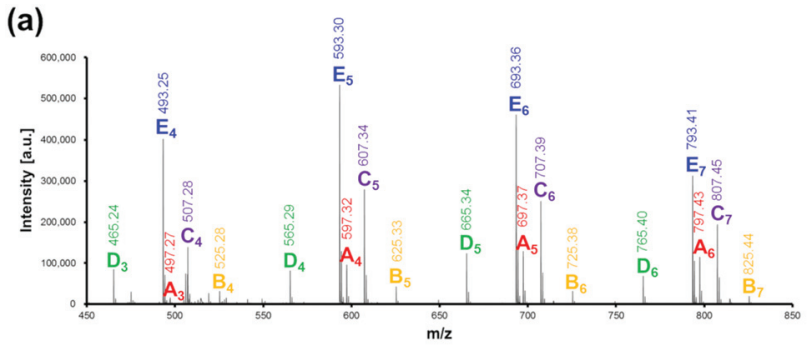

(b)

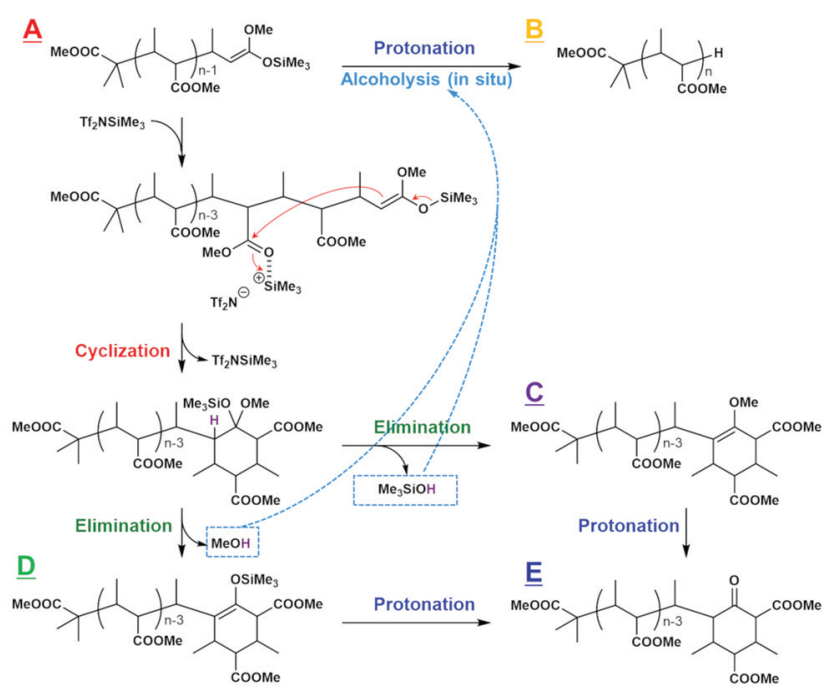

Fig. 4 MALDI-TOF-MS analysis of the reaction mixture in the GTP of MC. (a) MALDI-TOF-MS spectrum measured using dithranol as the matrix and $\mathrm{CF}_{3} \mathrm{COONa}$ as the ionizing agent. The polymerization was performed at a feed ratio of $[\mathrm{MC}]_{0} /[\mathrm{MTS}]_{0} /\left[\mathrm{Tf}_{2} \mathrm{NSiMe}_{3}\right]_{0}=3 / 1 / 0.03$ $\left([\mathrm{MC}]_{0}=1.7 \mathrm{M}\right)$, in $\mathrm{CH}_{2} \mathrm{Cl}_{2}$ at $20^{\circ} \mathrm{C}$ for $24 \mathrm{~h}$. (b) Proposed scheme of termination reactions predicted from the products and intermediates observed in the MALDI-TOF-MS spectrum.

ions (series A to E), all of which have mass-ion intervals corresponding to a repeat unit of $m / z=100$ (in agreement with the molecular weight of MC). A detailed analysis of the mass spectrum reveals that the series $\mathrm{A}$ polymer corresponds to the structural formula $\left(\mathrm{CH}_{3}\right)_{2}\left[\mathrm{CH}_{3} \mathrm{OC}(=\mathrm{O})\right] \mathrm{C}-(\mathrm{MC})_{n-1}-\mathrm{CH}\left(\mathrm{CH}_{3}\right)-$ $\mathrm{HC}=\mathrm{C}\left(\mathrm{OCH}_{3}\right)\left(\mathrm{OSiMe}_{3}\right)$, and the series B polymer corresponds to the structural formula $\left(\mathrm{CH}_{3}\right)_{2}\left[\mathrm{CH}_{3} \mathrm{OC}(=\mathrm{O})\right] \mathrm{C}-(\mathrm{MC})_{n}-\mathrm{H}$. The former consists of linear living polymers possessing the chainend structure of a silyl ketene acetal, and the latter consists of protonated forms of the linear living polymers (in addition to protonolysis during the polymerization, the protonated chain ends observed by MALDI-TOF-MS can result from postpolymerization protonolysis, which might occur because of the acidic compounds present in the form of the matrix (dithranol)). The series E polymer is observed as a major component, and it corresponds to the polymer structures shown in Fig. 4(b). The series E polymer is formed by the cyclization reaction of the linear living polymer (series A), a well-known termination reaction in GTP systems. In addition, ${ }^{13} \mathrm{C}$ NMR studies suggest that such a cyclic structure could correspond to a keto-carbon, as shown in Fig. S1. $\dagger$ Furthermore, in the 
MALDI-TOF-MS spectrum, the series $\mathrm{C}$ and D polymers are also confirmed as intermediates of a transition from the series A to series E polymers.

These results reveal that the cyclization reaction of the linear living polymer proceeds with the formation of alcohols such as $\mathrm{MeOH}$ and $\mathrm{Me}_{3} \mathrm{SiOH}$, which are protic acids, as shown in Fig. 4(b). In addition, the alcohols generated in situ react immediately with the linear living polymer, and the living chain-end is deactivated. This is probably the reason why the polymers observed when polymerization stopped include the polymer of a linear form.

\section{Kinetic modeling}

We propose an overall reaction pathway for the GTP of alkyl crotonates using a silicon LA catalyst from the knowledge obtained above. Scheme 2 shows the proposed elementary reactions of this polymerization system. With regard to the equilibrium between the monomer and silicon LA catalyst, the monomer (M) coordinates with the silicon LA catalyst (C) with the rate constant $k_{1}$, and the activated monomer $\left(\mathbf{M}^{*}\right)$ is generated. In the reverse reaction, the rate constant is expressed as $k_{1} / K_{1}$ using the equilibrium constant $K_{1}$. Notably, we introduce one more equilibrium step, where one more monomer (M) coordinates with the activated monomer $\left(\mathbf{M}^{*}\right)$, leading to the generation of the inactive species $\left(\mathbf{M}_{2}^{*}\right)$, with a decreased activation degree. In the latter equilibrium step, the rate constant and equilibrium constant are denoted as $k_{2}$ and $K_{2}$, respectively.

The initiation or propagation step proceeds with the activated monomer $\left(\mathbf{M}^{*}\right)$ reacting with the initiator (I) or linear living polymer $\left(\mathrm{P}_{\mathrm{n}}^{\mathrm{L}}\right)$, respectively. For simplicity, the rate constants of the initiation and propagation reactions were considered to be similar because the structures of the initiator

$$
\begin{aligned}
& \text { Equilibrium between monomer and LA catalyst } \\
& M+C \stackrel{k_{1}}{\longleftarrow} M^{*} \text { (activespecies) } \quad \text { : : monomer } \\
& \begin{array}{rl}
k_{1} / k_{1} & I: \text { initiator } \\
& C: \text { LA catalyst }
\end{array} \\
& M^{*}+M \stackrel{k_{2}}{\underset{k_{2} / K_{2}}{\longrightarrow}} M_{2}^{*} \text { (inactive species) } \begin{array}{l}
C: L A \text { catalyst } \\
M^{*}: M / C=1 / 1 \text { (active species) } \\
M_{2}^{*}: M / C=2 / 1 \text { (inactive species) }
\end{array} \\
& P^{L}{ }_{n}: \text { linear living specie } \\
& p^{C}{ }_{n}: \text { cyclic form } \\
& \text { Initiation \& Propagation } \quad p^{D}{ }_{n}: \text { protonated form } \\
& M^{*}+I \stackrel{k_{i}\left(\approx k_{p}\right)}{\longrightarrow} P^{L}{ }_{1}+C \\
& M^{*}+P_{n}^{L} \stackrel{k_{p}}{\longrightarrow} P^{L}{ }_{n+1}+C \\
& \text { Cyclization \& Alcoholysis } \\
& P_{n}^{L}+C \stackrel{k_{c}}{\longrightarrow} P^{C}{ }_{n}+C+R^{\prime} O H \\
& P^{L}{ }_{n}+\mathrm{R}^{\prime} \mathrm{OH} \stackrel{k_{a}}{\longrightarrow} P^{D}{ }_{n}+\mathrm{R}^{\prime} \mathrm{OSiR}_{3} \\
& \mathrm{R}^{\prime} \mathrm{OH} \text { : alcohol generated in situ } \\
& k_{1}, k_{2}\left[\frac{L}{\text { mol-s }}\right] \text { : rate constant of association }\left(=10^{2} \times k_{p}\right) \\
& k_{p}\left[\frac{L}{m o l} \cdot s\right] \text { :rate constant of propagation } \\
& k_{c}\left[\frac{L}{\mathrm{~mol} \cdot \mathrm{s}}\right] \text { :rate constant of cyclization } \\
& k_{a}\left[\frac{L}{\mathrm{~mol} \cdot \mathrm{s}}\right] \text { : rate constant of alcoholysis } \\
& K_{1}, K_{2}\left[\frac{L}{\text { mol }}\right] \text { : equilibrium constant }
\end{aligned}
$$

Scheme 2 Elementary reactions in the GTP system of an alkyl crotonate using a silicon LA catalyst. The definition of the rate constants $k_{1}$ and $k_{2}$ for the equilibrium between the monomer and catalyst, the rate constant $k_{\mathrm{i}}$ for initiation, the rate constant $k_{\mathrm{p}}$ for propagation, the rate constant $k_{\mathrm{c}}$ for cyclization, the rate constant $k_{\mathrm{a}}$ for alcoholysis, and the equilibrium constants $K_{1}$ and $K_{2}$ for the equilibrium between the monomer and catalyst are shown. and the chain-end of the linear living polymer were almost the same; therefore, we treated each reaction as the propagation of a living species using the rate constant $k_{\mathrm{p}}$.

In the termination reaction in the presence of a silicon LA catalyst $(\mathrm{C})$, the linear living polymer $\left(\mathrm{P}_{\mathrm{n}}^{\mathrm{L}}\right)$ was cyclized to a polymer having a terminal cyclic structure $\left(\mathrm{P}_{n}^{\mathrm{C}}\right)$ with the formation of an alcohol ( $\left.\mathrm{R}^{\prime} \mathrm{OH}\right)$. The rate constant of the cyclization reaction is $k_{\mathrm{c}}$. Moreover, the generated alcohol $\left(\mathrm{R}^{\prime} \mathrm{OH}\right)$ reacts with the linear living polymer $\left(\mathrm{P}_{n}^{\mathrm{L}}\right)$, and $\mathrm{P}_{\mathrm{n}}^{\mathrm{L}}$ is transformed to the deactivated form $\left(\mathrm{P}_{\mathrm{n}}^{\mathrm{D}}\right)$. The rate constant of the alcoholysis is $k_{\mathrm{a}}$. In this study, $k_{1}$ and $k_{2}$ were defined as $k_{1}=k_{2}$ $=10^{2} k_{\mathrm{p}}$, assuming that they were sufficiently large with respect to the polymerization reaction.

For each component, the rate law is expressed using a reaction time $(t(\mathrm{~s}))$ as follows (eqn (1)-(7)):

$$
\begin{aligned}
& \frac{\mathrm{d}[\mathbf{M}]}{\mathrm{d} t}=-k_{1}[\mathbf{M}][\mathrm{C}]+\frac{k_{1}}{K_{1}}\left[\mathbf{M}^{*}\right]-k_{2}[\mathbf{M}]\left[\mathbf{M}^{*}\right]+\frac{k_{2}}{K_{2}}\left[\mathbf{M}_{2}^{*}\right], \\
& \frac{\mathrm{d}\left[\mathbf{M}^{*}\right]}{\mathrm{d} t}=-k_{\mathrm{p}}\left[\mathbf{M}^{*}\right]\left[\mathrm{P}_{\mathrm{n}}^{\mathrm{L}}\right]-\left(-k_{1}[\mathbf{M}][\mathrm{C}]+\frac{k_{1}}{K_{1}}\left[\mathbf{M}^{*}\right]\right) \\
& +\left(-k_{2}[\mathbf{M}]\left[\mathbf{M}^{*}\right]+\frac{k_{2}}{K_{2}}\left[\mathbf{M}_{2}^{*}\right]\right)-\alpha k_{\mathrm{p}}\left[\mathbf{M}^{*}\right]\left[\mathrm{P}_{\mathrm{n}}^{\mathrm{C}}\right], \\
& \frac{\mathrm{d}\left[\mathbf{M}_{2}^{*}\right]}{\mathrm{d} t}=k_{2}[\mathbf{M}]\left[\mathbf{M}^{*}\right]-\frac{k_{2}}{K_{2}}\left[\mathbf{M}_{2}^{*}\right], \\
& \frac{\mathrm{d}[\mathrm{C}]}{\mathrm{d} t}=-k_{1}[\mathrm{M}][\mathrm{C}]+\frac{k_{1}}{K_{1}}\left[\mathrm{M}^{*}\right]+k_{\mathrm{p}}\left[\mathrm{M}^{*}\right]\left[\mathrm{P}_{\mathrm{n}}^{\mathrm{L}}\right], \\
& \frac{\mathrm{d}\left[\mathrm{P}_{\mathrm{n}}^{\mathrm{L}}\right]}{\mathrm{d} t}=-k_{\mathrm{c}}\left[\mathrm{P}_{\mathrm{n}}^{\mathrm{L}}\right][\mathrm{C}]-k_{\mathrm{a}}\left[\mathrm{P}_{\mathrm{n}}^{\mathrm{L}}\right]\left[\mathrm{R}^{\prime} \mathrm{OH}\right] \\
& +\alpha k_{\mathrm{p}}\left[\mathrm{M}^{*}\right]\left[\mathrm{P}_{\mathrm{n}}^{\mathrm{C}}\right] \text {, } \\
& \frac{\mathrm{d}\left[\mathrm{P}_{\mathrm{n}}^{\mathrm{C}}\right]}{\mathrm{d} t}=k_{\mathrm{c}}\left[\mathrm{P}_{\mathrm{n}}^{\mathrm{L}}\right][\mathrm{C}]-\alpha k_{\mathrm{p}}\left[\mathrm{M}^{*}\right]\left[\mathrm{P}_{\mathrm{n}}^{\mathrm{C}}\right] \\
& \frac{\mathrm{d}\left[\mathrm{R}^{\prime} \mathrm{OH}\right]}{\mathrm{d} t}=k_{\mathrm{c}}\left[\mathrm{P}_{\mathrm{n}}^{\mathrm{L}}\right][\mathrm{C}]-k_{\mathrm{a}}\left[\mathrm{P}_{\mathrm{n}}^{\mathrm{L}}\right]\left[\mathrm{R}^{\prime} \mathrm{OH}\right] .
\end{aligned}
$$

The parameter $\alpha$, which is assumed to be zero in this study, is the relative value of the rate constant of the propagation reaction from the cyclic form $\left(\mathrm{P}_{\mathrm{n}}^{\mathrm{C}}\right)$ toward the propagation reaction from the linear living species $\left(\mathrm{P}_{\mathrm{n}}^{\mathrm{L}}\right)$. The seven ordinary differential equations generated were solved numerically for all the simulations in this study. Subsequently, the monomer conversion $(x(\%))$ at $t(\mathrm{~s})$ was calculated as follows by using solved $[\mathrm{M}]$, and $\left[\mathbf{M}^{*}\right]$ and $\left[\mathbf{M}_{2}^{*}\right]$, which are recovered as free monomers after the polymerization is quenched with methanol, and the initial monomer concentration $[\mathbf{M}]_{0}$ (please note that $\left[\mathbf{M}^{*}\right]_{0}$ and $\left[\mathbf{M}_{2}^{*}\right]_{0}$ are zero):

$$
x(\%)=100\left(1-\frac{[\mathbf{M}]+\left[\mathbf{M}^{*}\right]+2\left[\mathbf{M}_{2}^{*}\right]}{[\mathbf{M}]_{0}}\right) .
$$

For further investigation of the alkyl crotonate GTP mechanism using a silicon LA catalyst, AdamsBDF curve-fitting analysis using Mathcad software was conducted using the monomer conversion data presented in Table 1 , which were acquired under the following conditions: the initial monomer 
(a)

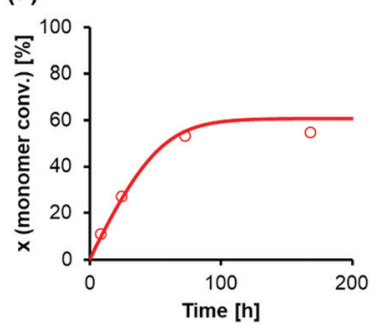

(d)

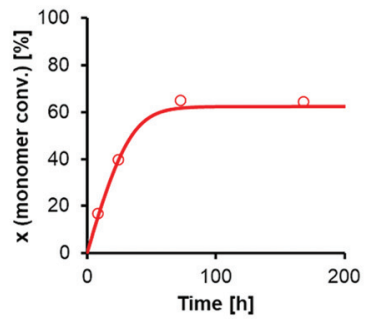

(g)

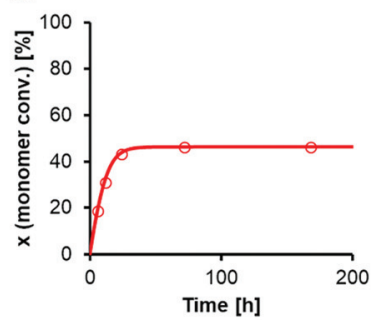

(b)

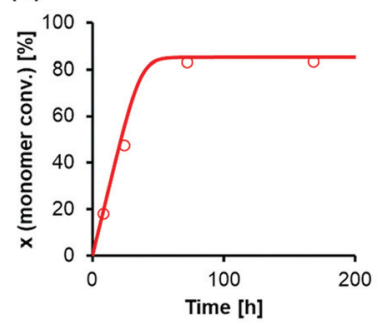

(e)

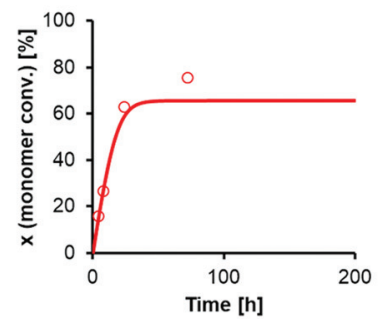

(h)

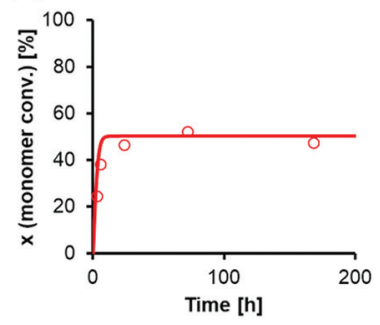

(c)

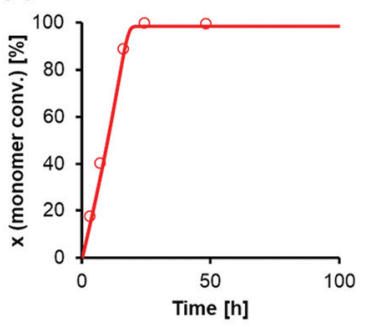

(f)

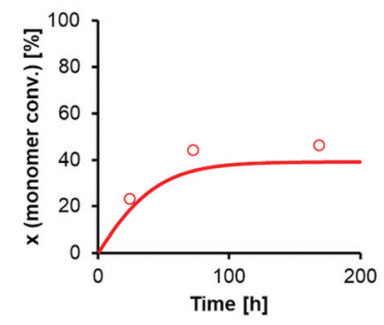

Conditions: $[\mathrm{EC}]_{0} /[\mathrm{MTS}]_{0} /\left[\mathrm{Tf}_{2} \mathrm{NSiMe}_{3}\right]_{0}$

(a) $2.0 \mathrm{M} / 0.0050 \mathrm{M} / 0.0050 \mathrm{M}$

(b) $2.0 \mathrm{M} / 0.010 \mathrm{M} / 0.0050 \mathrm{M}$

(c) $2.0 \mathrm{M} / 0.020 \mathrm{M} / 0.0050 \mathrm{M}$

(d) $1.5 \mathrm{M} / 0.0050 \mathrm{M} / 0.0050 \mathrm{M}$

e) $1.0 \mathrm{M} / 0.0050 \mathrm{M} / 0.0050 \mathrm{M}$

f) $1.0 \mathrm{M} / 0.0025 \mathrm{M} / 0.0025 \mathrm{M}$

(g) $1.0 \mathrm{M} / 0.0025 \mathrm{M} / 0.010 \mathrm{M}$

(h) $1.0 \mathrm{M} / 0.0025 \mathrm{M} / 0.040 \mathrm{M}$

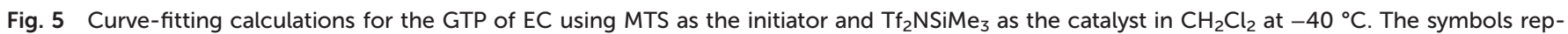

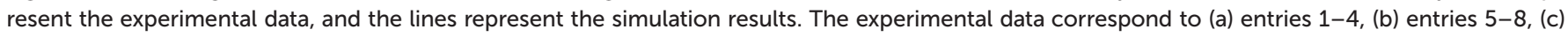
entries 9-14, (d) entries 15-18, (e) entries 19-22, (f) entries 23-25, (g) entries 26-30, and (h) entries 31-35 in Table 1.

concentration was 1.0-2.0 M, the initial initiator concentration was $0.0025-0.020 \mathrm{M}$, and the initial silicon LA catalyst concentration was 0.0025-0.040 M. In this analysis, the kinetic parameters shown in Scheme 2 were optimized, as the simulated and experimental data are in good agreement.

Fig. 5 shows the agreement between the simulated and experimental data for the GTP of EC using MTS as the initiator and $\mathrm{Tf}_{2} \mathrm{NSiMe}_{3}$ as the silicon LA catalyst at $-40^{\circ} \mathrm{C}$. The kinetic model constructed in this study agrees well with actual experiments in that despite the living-polymerization character of the GTP system, the propagation reaction declines, with unreacted monomer remaining. Table 2 summarizes the estimated kinetic parameters. Representative results are as follows: the rate constant of the propagation reaction $k_{\mathrm{p}}$ was $0.94 \mathrm{~L} \mathrm{~mol}^{-1} \mathrm{~s}^{-1}$, and the rate constant of the cyclization reaction $k_{\mathrm{c}}$ was $1.70 \mathrm{~L} \mathrm{~mol}^{-1} \mathrm{~s}^{-1}$.

\section{Temperature effect}

Next, we attempted to estimate the activation energies for the propagation, cyclization, and alcoholysis reactions $\left(E_{\mathrm{p}}, E_{\mathrm{c}}\right.$, and $E_{\mathrm{a}}$ ), as well as the standard enthalpy changes for equilibrium in the formation of $\mathbf{M}^{*}$ and $\mathbf{M}_{2}^{*}\left(\Delta H_{1}\right.$ and $\left.\Delta H_{2}\right)$. To confirm these parameters, polymerization experiments of EC were conducted using $\mathrm{Tf}_{2} \mathrm{NSiMe}_{3}$ and MTS under various temperature
Table 2 Estimated kinetic parameters $\left(k_{\mathrm{p}}, k_{\mathrm{c}}, k_{\mathrm{a}}, k_{1}\right.$, and $\left.K_{2}\right)$ of the GTP of EC using $\mathrm{Tf}_{2} \mathrm{NSiMe}_{3} / \mathrm{MTS}$ at $-40{ }^{\circ} \mathrm{C}$

\begin{tabular}{llll}
\hline Kinetic parameter & & Unit & Value \\
\hline Propagation & $k_{\mathrm{p}}$ & $\mathrm{L} \mathrm{mol}^{-1} \mathrm{~s}^{-1}$ & 0.94 \\
Cyclization & $k_{\mathrm{c}}$ & $\mathrm{L} \mathrm{mol}^{-1} \mathrm{~s}^{-1}$ & 1.70 \\
Alcoholysis & $k_{\mathrm{a}}$ & $\mathrm{L} \mathrm{mol}^{-1} \mathrm{~s}^{-1}$ & 0.01 \\
1st equilibrium & $K_{1}$ & $\mathrm{~L} \mathrm{~mol}^{-1}$ & 630 \\
2nd equilibrium & $K_{2}$ & $\mathrm{~L} \mathrm{~mol}^{-1}$ & 1.4 \\
\hline
\end{tabular}

conditions $\left(-10{ }^{\circ} \mathrm{C},-20{ }^{\circ} \mathrm{C}\right.$, and $\left.-30^{\circ} \mathrm{C}\right)$. Table 3 lists the monomer conversions under various temperature conditions. As the reaction temperature increased, polymerization stopped at a lower level of final monomer conversion. For example, the final monomer conversion at $-10^{\circ} \mathrm{C}$ was very low, $26 \%$ (entry 14 in Table 3). This result suggests that the termination reaction is significantly accelerated at higher temperatures, with the propagation reaction proceeding inferiorly.

AdamsBDF curve-fitting analysis with Mathcad software was conducted using the kinetic parameters estimated at $-40{ }^{\circ} \mathrm{C}$ (Table 2) and the monomer conversion experimental data presented in Table 3. Using the rate constant estimated at $-40{ }^{\circ} \mathrm{C}$ $\left(k_{-40}\right)$ and the activation energy $(E)$, the rate constant at temperature $T\left(k_{T}\right)$ is expressed as $k_{T}=k_{-40} \exp \left[(E / R)\left\{\left(1 /-40{ }^{\circ} \mathrm{C}\right)-\right.\right.$ 
Table 3 Results of EC polymerization using $\mathrm{Tf}_{2} \mathrm{NSiMe}_{3} / \mathrm{MTS}$ at various temperatures $^{a}$

\begin{tabular}{llllll}
\hline Entry & $\begin{array}{l}\text { Temperature } \\
\left({ }^{\circ} \mathrm{C}\right)\end{array}$ & $\begin{array}{l}\text { Time } \\
(\mathrm{h})\end{array}$ & $\begin{array}{l}\text { Conv. } \\
(\%)\end{array}$ & $\begin{array}{l}M_{\mathrm{n}}{ }^{c} \\
\left(\mathrm{~g} \mathrm{~mol}^{-1}\right)\end{array}$ & $\begin{array}{l}\Xi^{c} \\
\left(M_{\mathrm{w}} / M_{\mathrm{n}}\right)\end{array}$ \\
\hline 1 & -30 & 8 & 17.8 & 20100 & 1.16 \\
2 & & 24 & 36.6 & 45300 & 1.18 \\
3 & & 48 & 41.3 & 51400 & 1.24 \\
4 & & 72 & 41.3 & 51400 & 1.24 \\
5 & -20 & 2.5 & 10.9 & 11900 & 1.17 \\
6 & & 5 & 18.4 & 21200 & 1.18 \\
7 & & 10 & 27.7 & 33200 & 1.23 \\
8 & & 24 & 32.6 & 38900 & 1.32 \\
9 & & 72 & 32.3 & 39100 & 1.31 \\
10 & -10 & 2.5 & 14.7 & 17500 & 1.21 \\
11 & & 5 & 22.3 & 27100 & 1.26 \\
12 & & 10 & 24.9 & 30700 & 1.32 \\
13 & & 24 & 25.7 & 31100 & 1.33 \\
14 & & 72 & 25.6 & 31600 & 1.32
\end{tabular}

${ }^{a}$ Performed on an aluminum block under an argon atmosphere. $\mathrm{CH}_{2} \mathrm{Cl}_{2}$ was used as the reaction solvent. The conditions were as follows: $[\mathrm{EC}]_{0}=2.0 \mathrm{M},[\mathrm{MTS}]_{0}=0.0050 \mathrm{M}$, and $\left[\mathrm{Tf}_{2} \mathrm{NSiMe}_{3}\right]_{0}=0.0050$ M. ${ }^{b}$ Monomer conversion was calculated from the sum of the weights of the hexane-insoluble and hexane-soluble parts. ${ }^{c}$ Number-averaged molecular weight $\left(M_{\mathrm{n}}\right)$ and dispersity $(D)$ were determined using conventional GPC against PSt standards in $\mathrm{CHCl}_{3}$.

$(1 / T)\}]$, as per the Arrhenius equation. Using the equilibrium constant estimated at $-40^{\circ} \mathrm{C}\left(K_{-40}\right)$ and the standard enthalpy change $(\Delta H)$, the equilibrium constant at the temperature $T$ $\left(K_{T}\right)$ is expressed as $K_{T}=\exp \left[(\Delta H / R)\left\{\left(1 /-40{ }^{\circ} \mathrm{C}\right)-(1 / T)\right\}+\ln \right.$ $\left.\left(K_{-40}\right)\right]$, as per the van't Hoff equation. In this analysis, the activation energies $\left(E_{\mathrm{p}}, E_{\mathrm{c}}\right.$, and $\left.E_{\mathrm{a}}\right)$ and standard enthalpy changes $\left(\Delta H_{1}\right.$ and $\left.\Delta H_{2}\right)$ were optimized, as the simulated and experimental data presented in Table 3 are in good agreement. Fig. 6 shows the agreement between the simulated and experimental data for the GTP of EC under various temperature conditions, and Table 4 lists the estimated parameters. Representative results are as follows: the activation energy of the propagation reaction $E_{\mathrm{p}}$ was $28.6 \mathrm{~kJ} \mathrm{~mol}^{-1}$, and the activation energy of the cyclization reaction $E_{\mathrm{c}}$ was $37.8 \mathrm{~kJ} \mathrm{~mol}^{-1}$. This result suggests that as the reaction temperature increased, the ratio of the reaction rate constants for the cyclization reaction toward the
Table 4 Estimated kinetic parameters $\left(E_{\mathrm{p}}, E_{\mathrm{c}}, E_{\mathrm{a}}, \Delta H_{1}\right.$, and $\left.\Delta H_{2}\right)$ for the GTP of EC using $\mathrm{Tf}_{2} \mathrm{NSiMe}_{3} / \mathrm{MTS}$

\begin{tabular}{lllr}
\hline Kinetic parameter & & Unit & Value \\
\hline Propagation & $E_{\mathrm{p}}$ & $\mathrm{kJ} \mathrm{mol}^{-1}$ & 28.6 \\
Cyclization & $E_{\mathrm{c}}$ & $\mathrm{kJ} \mathrm{mol}^{-1}$ & 37.8 \\
Alcoholysis & $E_{\mathrm{a}}$ & $\mathrm{kJ} \mathrm{mol}^{-1}$ & 29.8 \\
1st equilibrium & $\Delta H_{1}$ & $\mathrm{~kJ} \mathrm{~mol}^{-1}$ & -14.2 \\
2nd equilibrium & $\Delta H_{2}$ & $\mathrm{~kJ} \mathrm{~mol}^{-1}$ & -12.2
\end{tabular}

propagation reaction increased. Thus, the kinetic model constructed in this study can convincingly explain the actual polymerization behavior.

\section{Substituent effect}

Next, we conducted the GTP of EC using various silicon LA catalysts $\left(\mathrm{Tf}_{2} \mathrm{NSiR} 1 \mathrm{R} 2 \mathrm{R} 3\right)$ and SKAs $\left({ }^{\mathrm{R} 1 \mathrm{R} 2 \mathrm{R} 3} \mathrm{SKA}\right)$ to examine the effect of the trialkylsilyl moiety. The kinetic parameters for the polymerization reactions using $\mathrm{Tf}_{2} \mathrm{NSiEt}_{3} /{ }^{\mathrm{Et}_{3}} \mathrm{SKA}$, $\mathrm{Tf}_{2} \mathrm{NSi}^{t} \mathrm{BuMe}_{2} /{ }^{t \mathrm{BuMe}_{2}} \mathrm{SKA}$, and $\mathrm{Tf}_{2} \mathrm{NSi}^{\mathrm{i}} \mathrm{Pr}_{3} /{ }^{i \mathrm{Pr}_{3}} \mathrm{SKA}$ were investigated. All experiments were performed in the same manner as the polymerization experiment using $\mathrm{Tf}_{2} \mathrm{NSiMe}_{3} / \mathrm{MTS}$, except that the silicon LA catalysts were generated in situ by adding $\mathrm{Tf}_{2} \mathrm{NH}$ as a pre-catalyst to the corresponding SKAs (Scheme S1 $\dagger$ ). For the polymerization experiments using $\mathrm{Tf}_{2} \mathrm{NSi}^{\mathrm{i}} \mathrm{Pr}_{3} /{ }^{\mathrm{i} \mathrm{Pr}_{3}} \mathrm{SKA}$, 1,2-dichloroethane, which has a higher boiling point $\left(83.5^{\circ} \mathrm{C}\right)$ than $\mathrm{CH}_{2} \mathrm{Cl}_{2}\left(39.8^{\circ} \mathrm{C}\right)$, was used as the polymerization solvent. Table $\mathrm{S} 1 \dagger$ lists the monomer conversions in the GTP under various conditions.

In the kinetic analysis, a reference temperature $\left(T_{\mathrm{r}}\right)$, the temperature at which the monomer cannot be consumed fully, was first set for each system, because the kinetic model in this study includes both the propagation reaction and termination reaction, which significantly reduces the monomer consumption. The kinetic parameters $\left(k_{\mathrm{p}}, k_{\mathrm{c}}, k_{\mathrm{a}}, K_{1}\right.$, and $\left.K_{2}\right)$ were estimated at the reference temperature $\left(\mathrm{Tf}_{2} \mathrm{NSiEt}_{3} /{ }^{\mathrm{Et}_{3}} \mathrm{SKA}, T_{\mathrm{r}}=\right.$

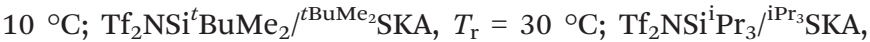
$T_{\mathrm{r}}=40^{\circ} \mathrm{C}$ ). AdamsBDF curve-fitting analyses using Mathcad software were conducted using the monomer conversion data (a)

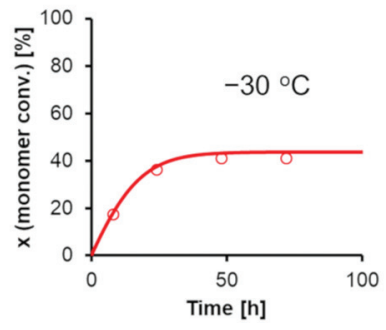

(b)

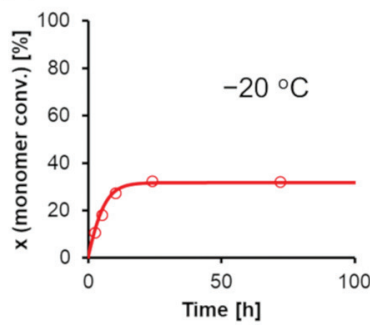

(c)

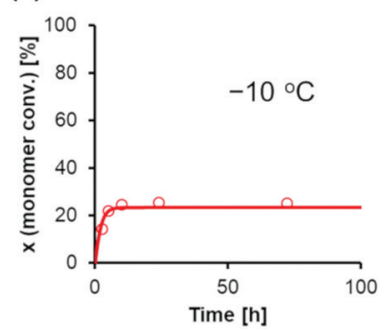

Fig. 6 Curve-fitting calculations for the GTP of EC using MTS as the initiator and $\mathrm{Tf}_{2} \mathrm{NSiMe}_{3}$ as the catalyst in $\mathrm{CH}_{2} \mathrm{Cl}_{2}$ at various temperatures (a: $-30{ }^{\circ} \mathrm{C}, \mathrm{b}:-20^{\circ} \mathrm{C}$, and $\mathrm{c}:-10{ }^{\circ} \mathrm{C}$ ). The conditions are as follows: $[\mathrm{EC}]_{0}=2.0 \mathrm{M},[\mathrm{MTS}]_{0}=0.0050 \mathrm{M}$, and $\left[\mathrm{Tf}_{2} \mathrm{NSiMe}_{3}\right]_{0}=0.0050 \mathrm{M}$. The symbols represent experimental data, and the lines represent simulation results. The experimental data correspond to (a) entries 1-4, (b) entries 5-9, and (c) entries 10-14 in Table 3. 
Table 5 Estimated kinetic parameters $\left(k_{\mathrm{p}}, k_{\mathrm{c}}, k_{\mathrm{a}}, K_{1}\right.$, and $\left.K_{2}\right)$ for the GTP of EC using silicon LA catalysts and SKAs having various trialkylsilyl moieties at $T_{\mathrm{r}}$

\begin{tabular}{llllll}
\hline & & & $\left.\mathrm{Tf}_{2} \mathrm{NSiEt}_{3}{ }^{\text {Et }_{3}} \mathrm{SKA}_{\left(T_{\mathrm{r}}=10\right.}{ }^{\circ} \mathrm{C}\right)$ & $\mathrm{Tf}_{2} \mathrm{NSi}^{t} \mathrm{BuMe}_{2} /{ }^{t \mathrm{BuMe}_{2}} \mathrm{SKA}\left(T_{\mathrm{r}}=30{ }^{\circ} \mathrm{C}\right)$ & $\mathrm{Tf}_{2} \mathrm{NSi}^{\mathrm{i}} \mathrm{Pr}_{3} /{ }^{\mathrm{Pr}_{3}} \mathrm{SKA}^{a}\left(T_{\mathrm{r}}=40{ }^{\circ} \mathrm{C}\right)$ \\
\hline Propagation & $k_{\mathrm{p}}$ & $\mathrm{L} \mathrm{mol}^{-1} \mathrm{~s}^{-1}$ & 4.49 & 6.20 & 1.80 \\
Cyclization & $k_{\mathrm{c}}$ & $\mathrm{L} \mathrm{mol}^{-1} \mathrm{~s}^{-1}$ & 1.08 & 0.53 & 0.16 \\
Alcoholysis & $k_{\mathrm{a}}$ & $\mathrm{L} \mathrm{mol}^{-1} \mathrm{~s}^{-1}$ & 0.45 & 0.45 & 0.10 \\
1st equilibrium & $K_{1}$ & $\mathrm{~L} \mathrm{~mol}^{-1}$ & 130 & 81 & 71 \\
2nd equilibrium & $K_{2}$ & $\mathrm{~L} \mathrm{~mol}^{-1}$ & 0.11 & 0.07 & 0.07
\end{tabular}

${ }^{a}$ The parameter $\alpha$ was set to 0.1 in the case of $\operatorname{Tf}_{2} \mathrm{NSi}^{\mathrm{i}} \operatorname{Pr}_{3} /{ }^{\mathrm{iPr}}{ }^{3} \mathrm{SKA}$

presented in Table $\mathrm{S} 1 . \dagger$ In the analyses, the parameter $\alpha$ was set to zero, except for the case of $\mathrm{Tf}_{2} \mathrm{NSi}^{\mathrm{i}} \mathrm{Pr}_{3}{ }^{\text {iPr }}{ }^{{ }_{3}} \mathrm{SKA}(\alpha=0.1)$. The estimated kinetic parameters are listed in Table 5, and the curve-fitting results are shown in Fig. S2-S4. $\dagger$ In all cases, the simulations reproduced the experimental data well. Next, we attempted to estimate the activation energies of the propagation, cyclization, and alcoholysis reactions $\left(E_{\mathrm{p}}, E_{\mathrm{c}}\right.$, and $\left.E_{\mathrm{a}}\right)$, as well as the standard enthalpy changes for equilibrium in the formation of $\mathbf{M}^{*}$ and $\mathbf{M}_{2}^{*}\left(\Delta H_{1}\right.$ and $\left.\Delta H_{2}\right)$ for each system. The analyses were conducted using the estimated kinetic parameters $\left(k_{\mathrm{p}}, k_{\mathrm{c}}, k_{\mathrm{a}}, K_{1}\right.$, and $\left.K_{2}\right)$ at $T_{\mathrm{r}}$ and the monomer conversion data under various temperature conditions (entries 1-4 and 17-36 in Table S1† for $\mathrm{Tf}_{2} \mathrm{NSiEt}_{3} /{ }^{\mathrm{Et}_{3}} \mathrm{SKA}$, entries 37-42 and 55-66 in Table $\mathrm{S} 1 \dagger$ as for $\mathrm{Tf}_{2} \mathrm{NSi}^{t} \mathrm{BuMe}_{2} /{ }^{t \mathrm{BuMe}_{2}} \mathrm{SKA}$, and entries 67-73 and 86-102 in Table $\mathrm{S} 1 \dagger$ as for $\mathrm{Tf}_{2} \mathrm{NSi}^{\mathrm{i}} \mathrm{Pr}_{3} /{ }^{\mathrm{iPr}}{ }_{3} \mathrm{SKA}$ ), in the manner described in the preceding subsection. The estimated kinetic parameters $\left(E_{\mathrm{p}}, E_{\mathrm{c}}, E_{\mathrm{a}}, \Delta H_{1}\right.$, and $\left.\Delta H_{2}\right)$ for each system are listed in Table 6 , and the curve-fitting results are shown in Fig. S5-S7. $\dagger$ Fig. 7 shows the relative values of $E_{\mathrm{p}}$ and $E_{\mathrm{c}}$ for each system with respect to those for the $\mathrm{Tf}_{2} \mathrm{NSiMe}_{3} / \mathrm{MTS}$ system.

In all cases, $E_{\mathrm{c}}$ was large with respect to $E_{\mathrm{p}}$, indicating that the acceleration of the cyclization reaction rate with increasing polymerization temperature is greater than that of the propagation reaction. Furthermore, the values of both $E_{\mathrm{p}}$ and $E_{\mathrm{c}}$ increase in the order $\mathrm{Tf}_{2} \mathrm{NSi}^{\mathrm{i}} \mathrm{Pr}_{3}{ }{ }{ }^{\mathrm{Pr}_{3}} \mathrm{SKA}>$ $\mathrm{Tf}_{2} \mathrm{NSi}^{t} \mathrm{BuMe}_{2} /{ }^{t \mathrm{BuMe}_{2}} \mathrm{SKA}>\mathrm{Tf}_{2} \mathrm{NSiEt}_{3} /{ }^{\mathrm{Et}_{3}} \mathrm{SKA}>\mathrm{Tf}_{2} \mathrm{NSiMe}_{3} / \mathrm{MTS}$. The trialkylsilyl group steric hindrance has previously been reported to increase in the order ${ }^{\mathrm{i}} \mathrm{Pr}_{3} \mathrm{Si}>{ }^{t} \mathrm{BuMe}_{2} \mathrm{Si}>\mathrm{Et}_{3} \mathrm{Si}>$ $\mathrm{Me}_{3} \mathrm{Si}^{24,25}$ Thus, the results of the present study confirm that the steric hindrance of the trialkylsilyl moiety of a silicon LA catalyst and an SKA can affect both the propagation and cyclization reactions of the GTP of alkyl crotonates. Notably, as

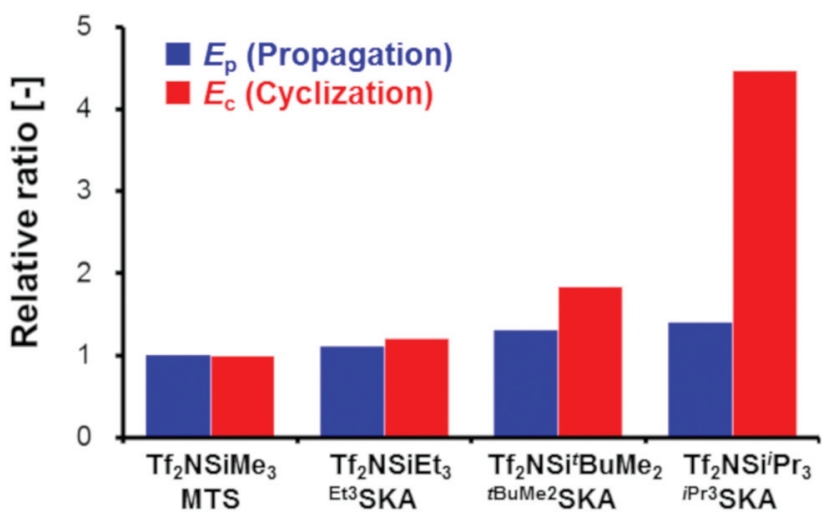

Fig. 7 Comparison of $E_{\mathrm{p}}$ and $E_{\mathrm{c}}$ for each trialkylsilyl moiety system with those for the $\mathrm{Tf}_{2} \mathrm{NSiMe}$ /MTS system. The blue bars show the relative values of $E_{\mathrm{p}}$, and the red bars show the relative values of $E_{\mathrm{c}}$ versus the case of $\mathrm{Tf}_{2} \mathrm{NSiMe}_{3} / \mathrm{MTS}$

shown in Fig. 7, the influence of the steric hindrance of the trialkylsilyl moiety is more pronounced for the cyclization reaction than for the propagation reaction. This result suggests that changing the trialkylsilyl moiety is an effective strategy to prioritize the propagation reaction over the termination reaction, which mainly consists of a cyclization reaction, in a certain temperature range. When the initial concentration of each component was fixed to $[\mathrm{EC}]_{0}=2.0 \mathrm{M},\left[{ }^{\mathrm{R} 1 \mathrm{R} 2 \mathrm{R} 3} \mathrm{SKA}\right]_{0}=$ $0.0050 \mathrm{M}$, and $\left[\mathrm{Tf}_{2} \mathrm{NSiR} 1 \mathrm{R} 2 \mathrm{R} 3\right]_{0}=0.0050 \mathrm{M}$, the monomer was fully consumed in the case of $\mathrm{Tf}_{2} \mathrm{NSiEt}_{3} /{ }^{\mathrm{Et}_{3}} \mathrm{SKA}$ at $-10{ }^{\circ} \mathrm{C}$ (entry 32 in Table $\mathrm{S} 1 \dagger$ ), $\mathrm{Tf}_{2} \mathrm{NSi}^{t} \mathrm{BuMe}_{2} /{ }^{t \mathrm{BuMe}_{2}} \mathrm{SKA}$ at $15{ }^{\circ} \mathrm{C}$ (entries 61 and 62 in Table $\mathrm{S} 1 \dagger$ ), and $\mathrm{Tf}_{2} \mathrm{NSi}^{\mathrm{i}} \mathrm{Pr}_{3}{ }^{i \mathrm{Pr}_{3}} \mathrm{SKA}$ at $40{ }^{\circ} \mathrm{C}$ (entry 73 in Table $\mathrm{S} 1 \dagger$ ). However, in the case of $\mathrm{Tf}_{2} \mathrm{NSiMe}_{3} / \mathrm{MTS}$, full conversion of the monomer could not be achieved even at a low temperature of $-40^{\circ} \mathrm{C}$ (entry 4 in Table 1$)$.

Table 6 Estimated kinetic parameters $\left(E_{\mathrm{p}}, E_{\mathrm{c}}, E_{\mathrm{a}}, \Delta H_{1}\right.$, and $\left.\Delta H_{2}\right)$ for the GTP of EC using silicon LA catalysts and SKAs having various trialkylsilyl moieties

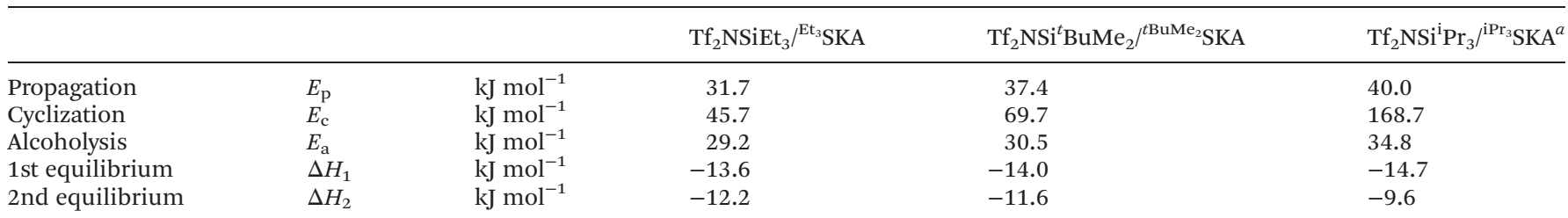

${ }^{a}$ The parameter $\alpha$ was set to 0.1 in the case of $\mathrm{Tf}_{2} \mathrm{NSi}^{\mathrm{i}} \mathrm{Pr}_{3}{ }^{i \mathrm{Pr}_{3}} \mathrm{SKA}$. 


\section{Conclusions}

In conclusion, we demonstrated the first example of a kinetic model of the GTP of alkyl crotonates including both the propagation and termination reactions. The kinetic model employs a new concept related to the equilibrium between a monomer and a silicon LA catalyst. Furthermore, we suggested that an inactive species might be generated from the coordination of another monomer to the activated monomer. Moreover, the MALDI-TOF-MS analysis of the reaction mixture revealed that the termination occurred both as a cyclization reaction of the linear living polymer and as an alcoholysis (in situ) of the linear living polymer, via the alcohols generated from the cyclization reaction.

The constructed kinetic model can convincingly reproduce the experimentally observed polymerization behavior. In addition, the examination of a trialkylsilyl moiety effect on the silicon LA catalyst and initiator revealed that the steric hindrance of the trialkylsilyl moiety strongly affected the elementary reactions, particularly the propagation and cyclization reactions, in this GTP system.

Further investigations on not only the steric factor but also the electronic factor of various silyl moieties of the silicon LA catalyst and initiator are necessary to establish an optimized, efficient, and manageable GTP system for alkyl crotonates.

\section{Author contributions}

M. I. and Y. T. designed, performed the experiments and analyzed the data. M. I. and Y. T. co-wrote the paper. All the authors discussed the results and commented on the manuscript.

\section{Conflicts of interest}

There are no conflicts to declare.

\section{Acknowledgements}

We thank Toshifumi Nishida and Satoshi Ishida of the analysis technology center at Nippon Shokubai Co., Ltd for assistance with the preparation of the computational results. This research was financially supported by JSPS KAKENHI Grant Numbers 26410199 and 18K05210. This paper is based on results obtained with the support of the RIKEN-AIST Joint Research Fund (Full research).

\section{Notes and references}

1 K. Weissermel and H. J. Arpe, Industrial Organic Chemistry, Wiley-VCH, Weinheim, 2003.

2 J. Blumenstein, J. Albert, R. P. Schulz and C. Kohlpaintner, Crotonaldehyde and Crotonic Acid in ULLMANN'S
Encyclopedia of Industrial Chemistry, Wiley-VCH, Weinheim, 2015.

3 M. L. Miller and J. Skogman, J. Polym. Sci., Part A: Gen. Pap., 1964, 2, 4551.

4 T. Makimoto, K. Tanabe and T. Tsuruta, Makromol. Chem., 1966, 99, 279.

5 T. Tsuruta, T. Makimoto and T. Miyazako, Makromol. Chem., 1967, 103, 128.

6 R. K. Graham, J. E. Moore and J. A. Powell, J. Appl. Polym. Sci., 1967, 11, 1797.

7 T. Tsuruta, T. Makimoto and K. Tanabe, Makromol. Chem., 1968, 114, 182.

8 Y. Takenaka and H. Abe, Macromolecules, 2019, 52, 4052.

9 Y. Takenaka and H. Abe, Jpn. Pat, 6342699, June 13, 2018.

10 K. Matyjaszewski and N. V. Tsarevsky, J. Am. Chem. Soc., 2014, 136, 6513.

11 N. J. Treat, H. Sprafke, J. W. Kramer, P. G. Clark, B. E. Barton, J. R. Alaniz, B. P. Fors and C. J. Hawker, J. Am. Chem. Soc., 2014, 136, 16096.

12 W. J. Brittain and I. B. Dicker, Macromolecules, 1989, 22, 1054.

13 W. J. Brittain and I. B. Dicker, Makromol. Chem., Macromol. Symp., 1993, 67, 373.

14 K. Takata, K. Fuchise, Y. Chen, T. Satoh and T. Kakuchi, J. Polym. Sci., Part A: Polym. Chem., 2012, 50, 3560 .

15 K. Ute, T. Tarao, S. Nakao and T. Kitayama, Polymer, 2003, 44, 7869.

16 A. Zheng, L. Su, Z. Li, G. Zou, X. Xu and Y. Guan, RSC Adv., 2017, 7, 53996.

17 Z. Li, J. Chen, G. Zou, T. Zhang, D. Wei, X. Xu, Y. Guan and A. Zheng, J. Polym. Sci., Part A: Polym. Chem., 2019, 57, 1130.

18 J. M. Wieting, T. J. Fisher, A. G. Schafer, M. D. Visco, J. C. Gallucci and A. E. Mattson, Eur. J. Org. Chem., 2015, 525.

19 M. J. Frisch, G. W. Trucks, H. B. Schlegel, G. E. Scuseria, M. A. Robb, J. R. Cheeseman, G. Scalmani, V. Barone, B. Mennucci, G. A. Petersson, H. Nakatsuji, M. Caricato, X. Li, H. P. Hratchian, A. F. Izmaylov, J. Bloino, G. Zheng, J. L. Sonnenberg, M. Hada, M. Ehara, K. Toyota, R. Fukuda, J. Hasegawa, M. Ishida, T. Nakajima, Y. Honda, O. Kitao, H. Nakai, T. Vreven, J. A. Montgomery, J. E. Peralta, F. Ogliaro, M. Bearpark, J. J. Heyd, E. Brothers, K. N. Kudin, V. N. Staroverov, T. Keith, R. Kobayashi, J. Normand, K. Raghavachari, A. Rendell, J. C. Burant, S. S. Iyengar, J. Tomasi, M. Cossi, N. Rega, J. M. Millam, M. Klene, J. E. Knox, J. B. Cross, V. Bakken, C. Adamo, J. Jaramillo, R. Gomperts, R. E. Stratmann, O. Yazyev, A. J. Austin, R. Cammi, C. Pomelli, J. W. Ochterski, R. L. Martin, K. Morokuma, V. G. Zakrzewski, G. A. Voth, P. Salvador, J. J. Dannenberg, S. Dapprich, A. D. Daniels, O. Farkas, J. B. Foresman, J. V. Ortiz, J. Cioslowski and D. J. Fox, Gaussian 09, Revision E.01, Gaussian, Inc., Wallingford CT, 2013.

20 A. D. Becke, J. Chem. Phys., 1993, 98, 5648. 
21 C. Lee, W. Yang and R. G. Parr, Phys. Rev. B: Condens. Matter Mater. Phys., 1988, 37, 785.

22 C. Chuit, R. J. P. Corriu, C. Reye and J. C. Young, Chem. Rev., 1993, 93, 1371.

23 M. G. Voronkov, E. A. Zel'bst, Y. V. Katkevich, A. A. Kashaev, V. S. Fundamenskii, Y. I. Bolgova,
O. M. Trofimova, N. F. Chernov, A. I. Albanov, Y. I. Baukov and V. A. Pestunovich, Dokl. Chem., 2005, 402, 77.

24 N. Shimizu, N. Takesue, S. Yasuhara and T. Inazu, Chem. Lett., 1993, 22, 1807.

25 N. Shimizu, N. Takesue, A. Yamamoto, T. Tsutsumi, S. Yasuhara and Y. A. Tsuno, Chem. Lett., 1992, 21, 1263. 